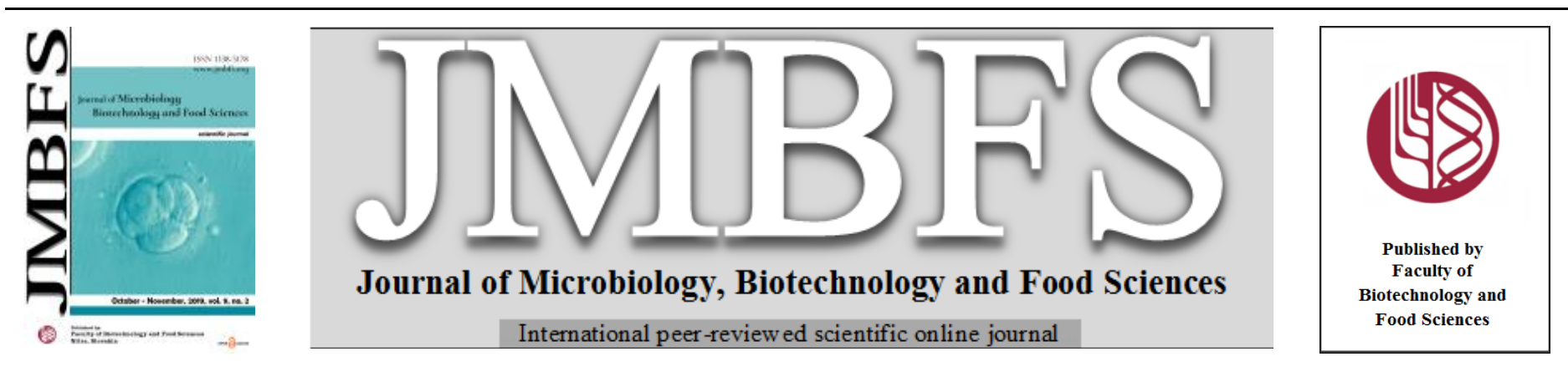

\title{
EXPERIMENTAL INVESTIGATIONS ON CAMELLIA KISSI WALL. FOR ANTIOXIDANT, ANTI-QUORUM SENSING AND ANTI-BIOFILM ACTIVITIES
}

\author{
Nagaraju Jalli ${ }^{1}$, Santhi Sri $K V^{* 1}$, Sairengpuii Hnamte ${ }^{2}$, Subhaswaraj Pattnaik ${ }^{2}$, Parasuraman Paramanantham $^{2}$, Busi Siddhardha $^{* 2}$
}

Address(es):

${ }^{1}$ Department of Foods and Nutritional Sciences, Acharya Nagarjuna University, Guntur-522510, India.

${ }^{2}$ Department of Microbiology, School of Life Sciences, Pondicherry University, Puducherry-605 014, India.

*Corresponding author: siddhardha.busi@gmail.com, drsanthi.anu@gmail.com

doi: $10.15414 / j m b f s .2020 .9 .4 .736-741$

\section{ARTICLE INFO}

Received 2. 2. 2019

Revised 1. 7. 2019

Accepted 2. 9. 2019

Published 3. 2. 2020

Regular article

OPEN $\partial_{\text {AcCESS }}$

\begin{abstract}
Plants are known for their widespread biological activities with special reference to the use in folkloric medicines for the treatment of several metabolic disorders and infectious diseases from ancient times. The presence of bioactive phytochemicals especially phenolic compounds, tocopherol, phytol etc. is responsible for the potential bioactivities of plants. In this work, the ability of ethanolic extract of Camellia kissi wall. to scavenge free radicals was investigated. Also, the anti-quorum sensing and anti-biofilm activity of C. kissi against Pseudomonas aeruginosa PAO1 was examined. The crude extract of $C$. kissi wall showed a significant antioxidant potential against DPPH and hydroxyl radicals with a scavenging percentage of $73.77 \pm 3.58$ and $75.3 \pm 4.45 \%$ respectively. The plant extract also significantly inhibited the QS mediated pyocyanin synthesis, bacterial motility and recalcitrant biofilm establishment in $P$. aeruginosa PAO1. Confocal laser scanning microscopic (CLSM) analysis confirmed the anti-biofilm efficacy. The in vitro anti QS potential of $C$. kissi wall. was further confirmed by molecular docking studies specifically targeting the QS transcriptional regulatory protein, LasR. The present result will provide ample avenues to exploit medicinal plants in attenuating the QS regulated microbial infections and oxidative stress in the post-antibiotic era.
\end{abstract}

Keywords: Antioxidant, ROS, Biofilm, Quorum sensing, Molecular docking, CLSM

\section{INTRODUCTION}

In the metabolic process of living organisms, oxidation reactions represent an intermediate step and produce free radicals. However, imbalance in the production and subsequent discharge of free radicals during the oxidation steps facilitate the production of strong reactive oxygen species (ROS) that plays an significant role in damage of the biological macromolecules such as nucleic acids, carbohydrates, proteins and lipids (Meena et al., 2012; Subhaswaraj $\boldsymbol{e t}$ al., 2017a; Rajkumari et al., 2018). The generation of free radicals or ROS is not only dute to the metabolic imbalance but also elevate during environmental stress and chronic bacterial infections (Cap et al., 2012). The chronic bacterial infections are generally associated with highly complex, bacterial population dependent cellular communication process called quorum sensing (QS). The QS network constitutes the production of specific signaling molecules with respect to cellular density, their interaction with specific cognate receptors and triggering the regulation of pathogenic phenotypes and biofilm establishment (Singh et al., 2009b). P. aeruginosa PAO1 is a nosocomial Gram negative bacterium cause cystic fibrosis, severe pulmonary infections and majority of hospital-acquired infections where QS network found to be an cause for its pathogenesis. (Vasavi et al., 2016). The QS regulatory network also controls the adverse effect of ROS can be neutralized by in-built antioxidant machinery including superoxide dismutase (SOD), glutathione peroxidase, glutathione reductase, catalase (CAT), $\beta$-carotene and vitamin A, C and E (Rath et al., 2011). However, when the generation of ROS exceeds certain limit, the integral antioxidant machinery fails to scavenge the highly reactive free radicals wher exogenous supply of antioxidant is necessary to neutralize the ROS mediated oxidative stress. In this context, plant derived phytochemicals especially polyphenolic group of compounds reported for radical scavenging activity and neutralization of oxidative stress (Luis et al., 2016). C. kissi wall. belongs to the genus Camellia, has received considerable attention due to its application in beverages industries, pharmacological properties and antioxidant potential (Bashir et al., 2014). In this work, antioxidant, anti QS and anti-biofilm potential of ethanolic extract of C. kissi wall. was determined. The ability of crude plant extract to regulate QS regulated virulence gene expression was also studied. The in vitro anti QS activity was further corroborated by molecular docking analysis that provided valuable information about the mechanism of QS inhibition.

\section{MATERIALS AND METHODS}

\section{Collection of plant and extract of crude}

The leaf samples of $C$. kissi wall. plant were obtained from Mizoram, India Leaves were thoroughly washed and dried. The dried plant materials were then homogenized into fine powder. Five grams of powdered plant powder was completely mixed in ethanol $(50 \mathrm{~mL})$ for 2-3 days. The plant infusions were allowed to pass through Whattmann filter paper and the residues were collected and concentrated under vacuum on a rotary evaporator at $40{ }^{\circ} \mathrm{C}$. Crude extract was stored for further use at $4{ }^{\circ} \mathrm{C}$.

\section{Reagents and media}

The chemicals utilized in the present work are 2, 2-Diphenyl-1-picrylhydrazyl (DPPH), 2-deoxy ribose, ethylene diamine tetraacetic acid (EDTA), thiobarbituric acid (TBA) and acridine orange. The reagents used in the study are trichloroacetic acid (TCA), sulphuric acid $\left(\mathrm{H}_{2} \mathrm{SO}_{4}\right)$, hydrochloric acid $(\mathrm{HCl})$, ferric chloride $\left(\mathrm{FeCl}_{3}\right)$, potassium ferricyanide $\left[\mathrm{K}_{3} \mathrm{Fe}(\mathrm{CN})_{6}\right]$ and sodium hydroxide $(\mathrm{NaOH})$. Chemicals and reagents were procured from HiMedia, laboratories Pvt Ltd, India.

\section{Determination of antioxidant potential}

\section{DPPH free radical scavenging assay}

DPPH free radical scavenging assay was performed by adopting the method illustrated by Udayaprakash et al. (2015). DPPH ( $0.2 \mathrm{mM}$ in methanol) was added to plant extract with varying concentrations ranging from $100 \mu \mathrm{g} / \mathrm{mL}$ to $500 \mu \mathrm{g} / \mathrm{mL}$. The resulting solution was incubated in dark at room temperature for $30 \mathrm{~min}$. The absorbance was measured at $517 \mathrm{~nm}$ after the incubation period. Along with the treated samples, a control experiment was also prepared without 
crude extract. The percentage DPPH scavenging was determined as per the following calculation. The $\mathrm{IC}_{50}$ value was also determined.

Scavenging $(\%)=\left(\mathrm{OD}_{517}\right.$ of the control $-\mathrm{OD}_{517}$ of the treatment $) \times 100$ $\mathrm{OD}_{517}$ of the control

\section{Determination of reducing power}

Reducing power was determined to evaluate the efficacy of $C$. kissi wall ethanolic extract in conversion of ferric $\left(\mathrm{Fe}^{3+}\right)$ to ferrous $\left(\mathrm{Fe}^{2+}\right)$ by reduction process which could be monitor by change of solution colour from colourless to Prussian blue. Briefly, phosphate buffer $(0.2 \mathrm{M}, \mathrm{pH} 6.6)$ and $1 \%\left[\mathrm{~K}_{3} \mathrm{Fe}(\mathrm{CN})_{6}\right]$ was added to a series of increasing concentrations of plant extract (100-500 $\mu \mathrm{g} / \mathrm{mL}$ ) in a ratio of 5:5:1. The reaction complex was subjected for incubation at $50{ }^{\circ} \mathrm{C}$ for 20 . After incubation, the reaction was terminated by mixing $10 \%$ wlv of TCA and the solution was centrifuged at $10,000 \mathrm{rpm}$ for $10 \mathrm{~min}$. The supernatant was diluted with deionized water and freshly prepared $\mathrm{FeCl}_{3}(0.1 \%$ $\mathrm{w} / \mathrm{v}$ ) in a ratio of 5:5:1. The optical density of the reaction complex was assessed at $700 \mathrm{~nm}$ (Do et al., 2014).

\section{Hydroxyl radical scavenging activity}

The efficacy of plant extract to scavenge highly reactive free hydroxyl radicals was investigated according to the protocol illustrated by Tounkara et al. (2014) Briefly, two experimental reactions were carried out by addition of sodium

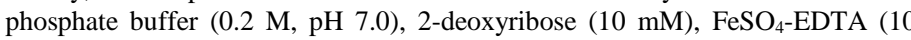
$\mathrm{mM})$ and $\mathrm{H}_{2} \mathrm{O}_{2}(10 \mathrm{mM})$ along with and without the presence of plant extract $(100-500 \mu \mathrm{g} / \mathrm{mL})$. The solution was incubated at $37^{\circ} \mathrm{C}$ for $4 \mathrm{~h}$ and then mixed with TCA $(2.8 \% \mathrm{w} / \mathrm{v})$ and TBA $(1 \% \mathrm{w} / \mathrm{v}$ in $\mathrm{NaOH})$. The mixture was boiled for $10 \mathrm{~min}$ and cooled to room temperature (RT). The optical density of the solution was read spectrophotometrically at $532 \mathrm{~nm}$ and hydroxyl radical scavenging was determined using the following equation,

Scavenging $(\%)=\left(\mathrm{OD}_{532}\right.$ of the control $-\mathrm{OD}_{532}$ of the treatment $) \times 100$ $\mathrm{OD}_{532} \mathrm{of}$ the control

\section{Total antioxidant activities}

The total antioxidant potential of leaf extract of $C$. kissi wall. was analyzed by standard procedure using phosphomolybdate. Briefly, different concentrations of leaf extract with varying concentration from $100 \mu \mathrm{g} / \mathrm{mL}$ to $500 \mu \mathrm{g} / \mathrm{mL}$ were added with reagent ( $0.6 \mathrm{M} \mathrm{H}_{2} \mathrm{SO}_{4}, 28 \mathrm{mM}$ sodium phosphate and $4 \mathrm{mM}$ ammonium molybdate) in 1:9 ratios. The reaction complex was incubated in a water bath a $95^{\circ} \mathrm{C}$ for $90 \mathrm{~min}$. After incubation, the temperature of reaction reduced to room temperature and the optical density was assessed at $695 \mathrm{~nm}$. Ascorbic acid equivalents obtained was used to express the total antioxidant activity (Do et al., 2014).

\section{Determination of anti QS and anti-biofilm activities}

\section{Bacterial strains and maintenance of culture}

The anti QS activity of $C$. kissi wall. extract was determined against biosensor strain, $C$. violaceum (MTCC 2656) and test microorganism, $P$. aeruginosa PAO1 The anti-biofilm efficacy was evaluated against $P$. aeruginosa PAO1. The bacterial cultures were obtained from Microbial type culture collection (MTCC), IMTECH, Chandigarh, India.

\section{Estimation of minimum inhibitory concentration (MIC)}

The MIC of $C$. kissi wall. extract against $P$. aeruginosa was calculated as per the recommendation of Clinical \& Laboratory Standards Institute (CLSI, 2014) using macrodilutions method. All the anti-QS and biofilm inhibition assays were conducted at sub-MIC concentration (El-Shaer et al., 2016).

\section{Anti-QS efficacy of plant extract against biosensor strain}

\section{Violacein inhibition activity}

The effect of $C$. kissi wall. extract on the syntheis of violacein by $C$. violaceum was evaluated (Husain et al., 2017). Briefly, C. violaceum was allowed to grow in presence or absence of sub-MIC of C. kissi wall. for $24 \mathrm{~h}$ at $30^{\circ} \mathrm{C}$. Violacein pigment from bacteria was precipitated by centrifuging the samples at 10,000 $\mathrm{rpm}$ for $10 \mathrm{~min}$. The precipitated pigment was dissolved in appropriate volumes of DMSO. The reaction mixture was centrifuged at $10,000 \mathrm{rpm}$ for $10 \mathrm{~min}$ and the absorbance of supernatant was read at $585 \mathrm{~nm}$ to quantify the violacein pigment.

\section{Anti QS and anti-biofilm potential of plant extract}

\section{Pyocynanin inhibition activity}

Pyocyanin is one of the most considerable QS mediated virulence trait produced by the test bacteria. The effect of sub-MIC of plant extract on pyocyanin production was studied according to the method described by Husain $\boldsymbol{e t}$ al. (2017) with slight modifications. Pyocyanin produced by bacteria after the treatment with plant extract was quantified in cell free culture supernatant by mixing the supernatant in chloroform (5:3 ratio). The reaction mixture was vortexed and the pyocyanin containing organic phase was re-extracted with $\mathrm{HC}$ $(0.2 \mathrm{M})$. The optical density of the aqueous phase contained acidified pigment was quantified at $520 \mathrm{~nm}$. A control experiment was performed without the addition of crude extract.

\section{Inhibition of bacterial motility}

The motility of test pathogen $P$. aeruginosa including swimming and swarming is regulated by QS network and plays promising role in the biofilm development and architecture. Briefly, the plant extract treated $P$. aeruginosa was point inoculated into specific swimming medium (composed of $1 \mathrm{~g}$ tryptone, $0.5 \mathrm{~g} \mathrm{NaCl}$ and $0.3 \mathrm{~g}$ agar agar in $100 \mathrm{ml}$ ) and swarming medium (composed of $1 \mathrm{~g}$ bacteriological peptone, $0.5 \mathrm{~g} \mathrm{NaCl}, 0.5 \mathrm{~g}$ filter sterilized glucose and $0.5 \mathrm{~g}$ agar in $100 \mathrm{ml})$ and incubated at $37^{\circ} \mathrm{C}$ (Packiavathy et al. 2014).

\section{Anti-biofilm activity using microscopic observation}

Briefly, C. kissi wall. extract treated $P$. aeruginosa was allowed to grow on the glass coverslips for an incubation time of $24 \mathrm{~h}$ at $37^{\circ} \mathrm{C}$. After $24 \mathrm{~h}$, Adhered biofilms present on the coverslip were stained with acridine orange $(0.1 \% \mathrm{w} / \mathrm{v})$ for $10 \mathrm{~min}$ under dark condition. Afterwards, the excess stain was removed from the coverslip and observed under CLSM (LSM 710, Carl Zeiss, Germany). A control experiment was also performed for $P$. aeruginosa PAO1 without the plant extract (Lewis Oscar et al. 2018).

\section{Gas Chromatography-Mass Spectrometric (GC-MS) analysis}

The phytochemical profile of ethanolic leaf extract of $C$. kissi wall. was analyzed by GC-MS (Thermo GC-Trace Ultra Version: 5.0, Thermo MS DSQ II equipped with a DB 35 - MS Capillary Standard non-polar column with dimensions of $30 \mathrm{~mm} \times 0.25 \mathrm{~mm} \mathrm{ID} \times 0.25 \mu \mathrm{m}$ film). The standard operating procedure was followed and the spectrum were recorded. Different phytochemical constituents of plant extract were identified by comparing the obtained spectrum with NIST libraries (Gomathi et al., 2015).

\section{Molecular docking studies}

Schrodinger maestro software version 9.2 was employed to study molecular docking studies. Along with that, the binding affinity of phytochemicals from GC-MS analysis and natural autoinducer to transcriptional receptor, LasR was analyzed. The three dimensional structure of LasR transcriptional regulator protein was recovered from Research Collaboratory for Structural Bioinformatics Protein Data Bank (RCSB PDB ID: 2UV0). The LasR protein was then subjected to preparation in protein preparation wizard of the software and grid was generated using Glide, version 5.7 in Schrodinger maestro software. Grid for Las $\mathrm{R}$ protein was defined around the residues, Tyr-56, Trp-60, Asp-73, Thr-75 and Ser-129 (active site residues) where the natural autoinducer binds with the LasR protein (Bottomley $\boldsymbol{e t}$ al., 2007). The above prepared grid was used for docking. Ligands obtained from pubchem database were subjected to ligand preparation using the software Ligprep module 2.5 in Schrodinger suite. Molecular docking was carried out with obtained protein and ligand.

\section{Statistical analysis}

All the tests were carried out in triplicates. The results were represented as the mean \pm standard deviation (SD). For each assay, a control experiment was performed without treating the test bacterium with plant extract.

\section{RESULTS AND DISCUSSION}

\section{Determination of antioxidant activity}

\section{DPPH free radical scavenging activity}

C. kissi wall. extract exhibited significant DPPH radical scavenging activity of of $24.0 \pm 1.04$ and $73.77 \pm 3.58 \%$ at a concentration of 100 and $500 \mu \mathrm{g} / \mathrm{mL}$ respectively. DPPH radical scavenging effect was contingent on the concentration of extract used. The plant extract showed an $\mathrm{IC}_{50}$ of $238.95 \mu \mathrm{g} / \mathrm{mL}$ (Figure 1). 


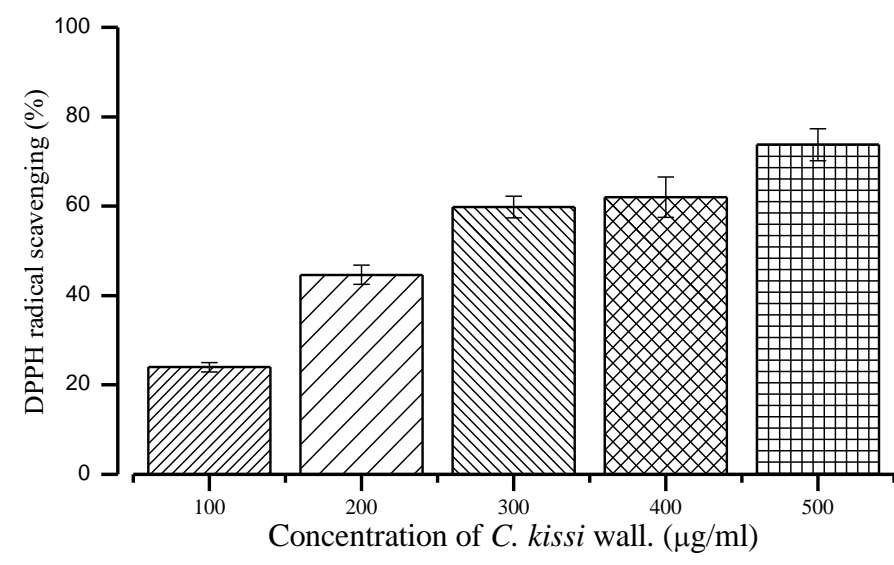

Figure 1 DPPH free radical scavenging potential of various concentrations (100$500 \mu \mathrm{g} / \mathrm{mL}$ ) of ethanolic leaf extract of C. kissi wall.

\section{Reducing power activity}

From reducing power assay experiment, it was noticed that with the increase in concentration of $C$. kissi wall. extract from 100 to $500 \mu \mathrm{g} / \mathrm{mL}$, a concomitant increase in the optical density from 0.3142 to 0.4935 was observed suggesting an increase in the reducing power (Figure 2). The ethanolic extract of $C$. kissi wall. showed an $\mathrm{IC}_{50}$ of $502.97 \mu \mathrm{g} / \mathrm{mL}$ for reducing power assay.

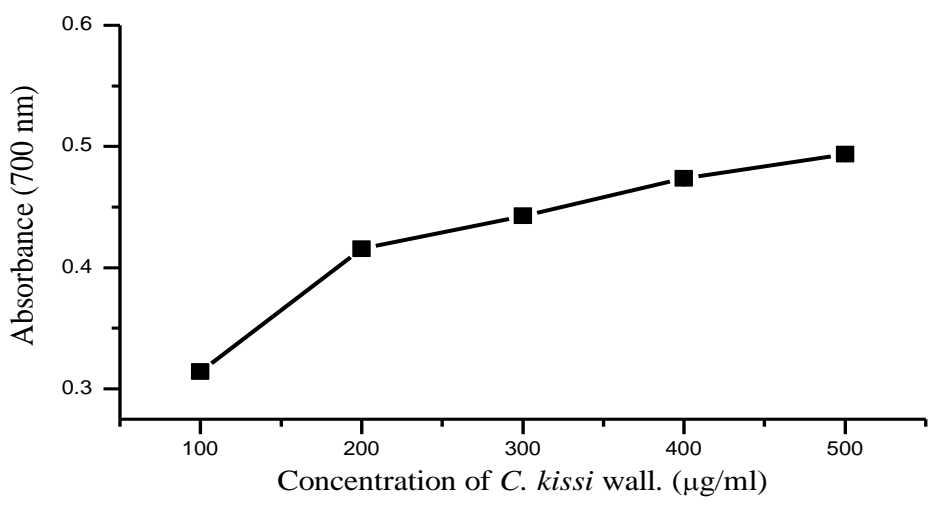

Figure 2 Determination of reducing power of different concentrations (100-500 $\mu \mathrm{g} / \mathrm{mL}$ ) of ethanolic leaf extract of C. kissi wall

\section{Hydroxyl radical scavenging activity}

Like DPPH scavenging effect, hydroxyl radical scavenging activity of extract was observed in a concentration dependent manner. Hydroxyl radical scavenging activity of leaf extract was observed with an $\mathrm{IC}_{50}$ of $256.97 \mu \mathrm{g} / \mathrm{mL}$ (Figure 3 ).

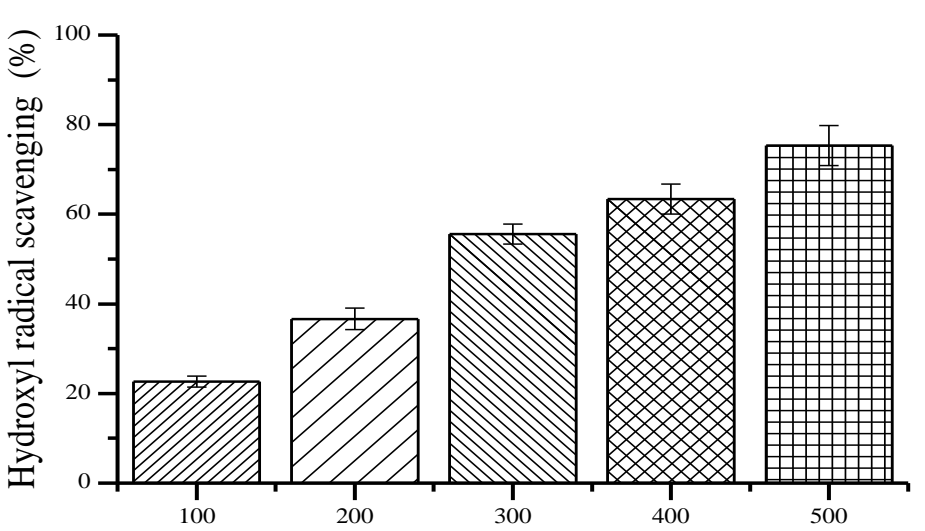

Concentrations of C. kissi wall. $(\mu \mathrm{g} / \mathrm{ml})$

Figure 3 Hydroxyl radical scavenging potential at varying concentrations (100$500 \mu \mathrm{g} / \mathrm{mL}$ ) of leaf extract of $C$. kissi wall.

\section{Total antioxidant activity}

Crude extract of plant elucidated a concomitant increase in the absorbance from $1.46 \pm 0.064$ to $3.90 \pm 0.126$ with the concentration of 100 and $500 \mu \mathrm{g} / \mathrm{mL}$ respectively. Plant extract showed an ascorbic acid equivalent of $137.12 \mu \mathrm{g} / \mathrm{mL}$ at $500 \mu \mathrm{g} / \mathrm{mL}$ (Figure 4).

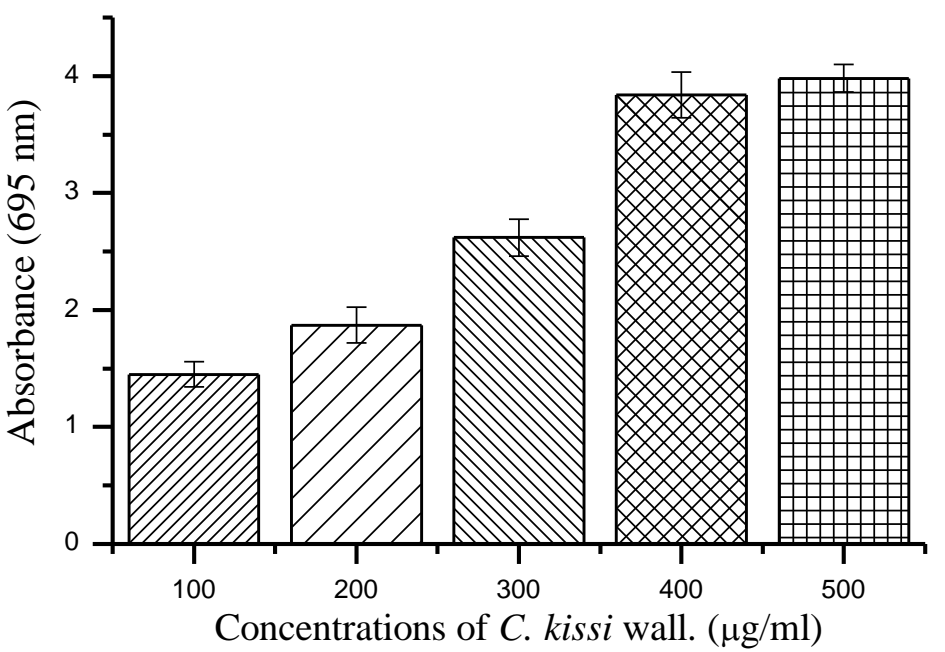

Figure 4 Total antioxidant activity of different concentrations $(100-500 \mu \mathrm{g} / \mathrm{mL})$ of leaf extract of $C$. kissi wall.

\section{Anti QS and anti-biofilm potential of plant extract}

\section{Minimum Inhibitory concentration}

The minimum inhibitory concentration of crude extract against test bacteria was observed as $1000 \mu \mathrm{g} / \mathrm{mL}$ and sub-MIC was fixed at 250 and $500 \mu \mathrm{g} / \mathrm{mL}$. All the anti QS and anti-biofilm activities were conducted at both the sub-MIC concentrations.

\section{Violacein inhibition activity against $C$. violaceum}

Violacein production in biomarker strain was inhibited by $56.25 \pm 3.47$ and 62.16 $\pm 3.21 \%$ on treatment with 250 and $500 \mu \mathrm{g} / \mathrm{mL}$ of leaf extract respectively (Figure 5).

\section{Pyocyanin inhibition activity against $P$. aeruginosa PAO1}

Inhibition of pyocycanin production was seen as purely contingent upon the concentrations of plant extract. Pyocyanin was inhibited in $P$. aeruginosa PAO to $50.27 \pm 2.69$ and $85.87 \pm 4.40 \%$ with 250 and $500 \mu \mathrm{g} / \mathrm{mL}$ of plant extract respectively (Figure 5).

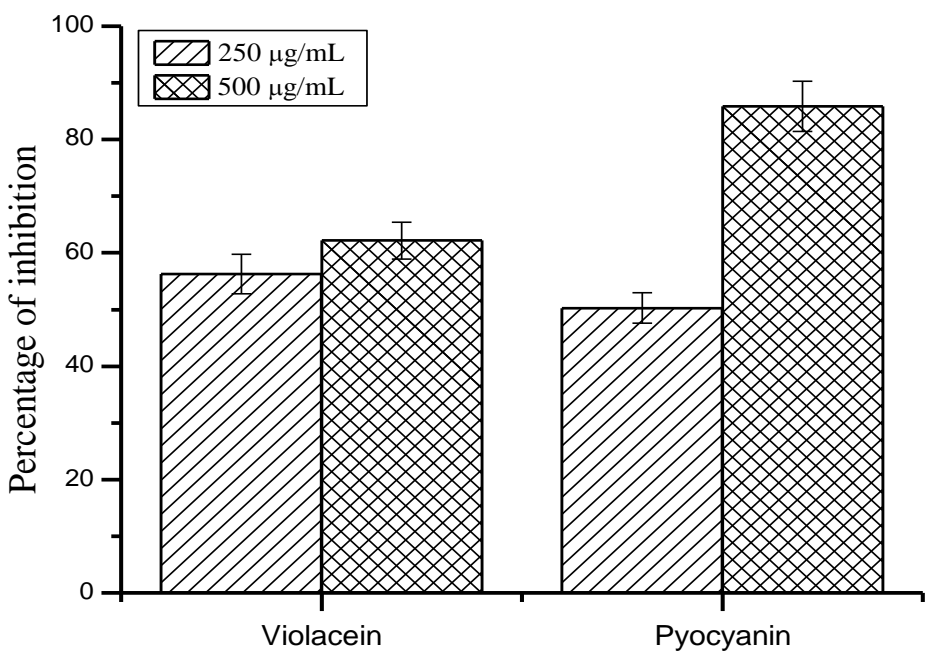

Figure 5 Effect of sub-MIC concentrations of C. kissi wall. $(250,500 \mu \mathrm{g} / \mathrm{mL})$ on synthesis of violacein and pyocyanin production in $C$. violaceum and in $P$. aeruginosa respectively.

\section{Inhibition of bacterial motility}

Motility of test bacteria was affected on incubation with sub-MIC of plant extract whereas untreated control did not show reduction in the motility (Figure 6). 

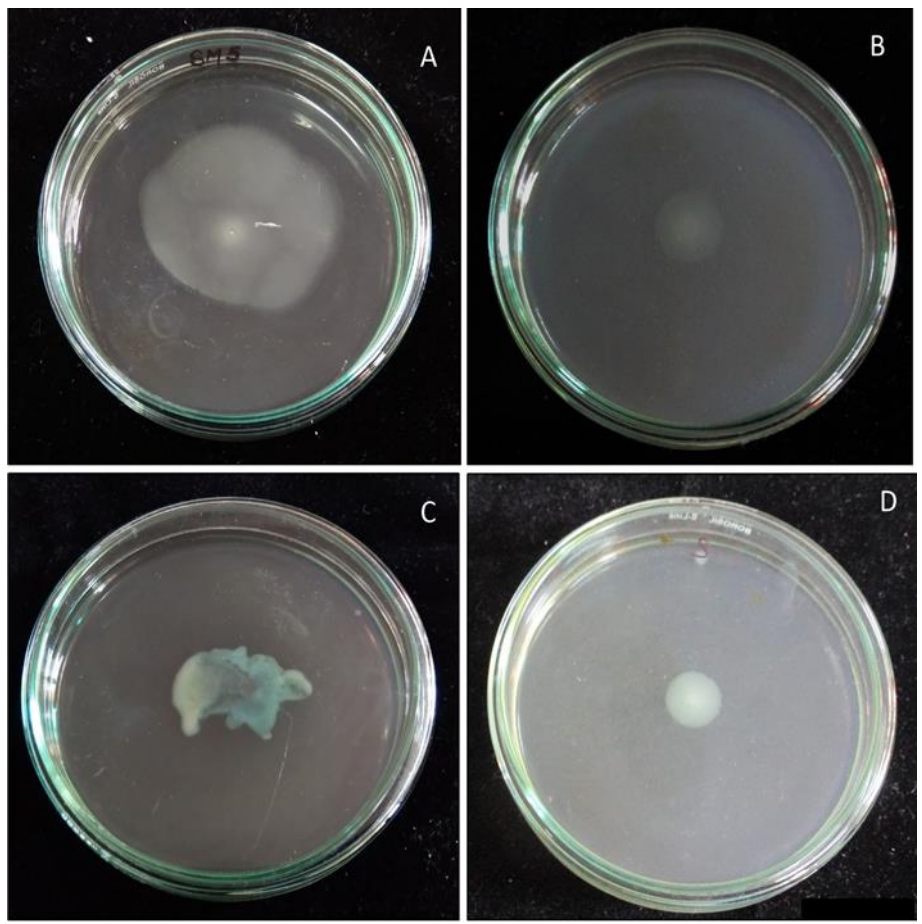

Figure 6 The effect of ethanolic leaf extract of C. kissi wall on swimming and swarming activities. (A) Swimming motility of test bacteria (untreated control), (B) Swimming motility of C. kissi wall. treated test bacteria, (C) Swarming motility of test bacteria (untreated control), (D) Swarming motility of $C$ kissi wall. treated test bacteria.

\section{Anti-biofilm activity using CLSM studies}

C. kissi wall. extract exhibited a significant anti-biofilm activity against the $24 \mathrm{~h}$ biofilms of $P$. aeruginosa PAO1 as observed from CLSM analysis when compared to untreated control with comparatively thick and highly compact biofilm architecture (Figure 7).
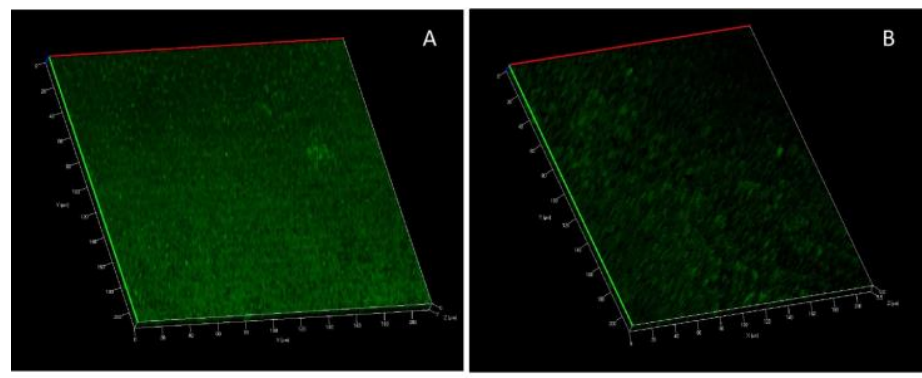

Figure 7 Anti-biofilm activity of ethanolic leaf extract of C. kissi wall. against bacterial biofilm (A) Biofilm development in test bacteria (untreated control),

(B) Inhibition of biofilm formation in test bacteria on treatment with C. kissi wall.

\section{GC-MS analysis}

$\alpha$-amyrin and $\beta$-amyrin were identified with 60.715 and 27.50 peak area (\%) which were relatively higher than other identified phytoconstituents after GC-MS analysis and NIST library search. The GC-MS spectrum and the identified compounds were listed in Table 1.

\begin{tabular}{|c|c|c|c|c|c|}
\hline SI no. & Compound name & $\begin{array}{l}\text { Peak } \\
\text { area }(\%)\end{array}$ & $\begin{array}{l}\text { Retention time } \\
\text { (min.) }\end{array}$ & Biological Activities & References \\
\hline 1 & Phytol & 2.06 & 16.68 & Antioxidant, Anti QS & $\begin{array}{l}\text { Santos et al } 2013 . \\
\text { Pejin } \text { et al } 2015 .\end{array}$ \\
\hline 2 & Olean-12-ene & 3.658 & 29.09 & Anti-inflammatory & Hussien et al, 2006. \\
\hline 3 & $\beta$-amyrin & 27.5 & 29.45 & Anti-bacterial & Ogwuche et al,2008 \\
\hline 4 & $\alpha$-amyrin & 5.025 & 29.65 & Anti-bacterial & Fermandes et al,2013 \\
\hline 5 & $\begin{array}{l}\text { 2R-Acetoxymethyl-1,3,3-trimethyl-4t-(3-methyl- } \\
\text { 2buten-1-yl) -1T-cycloh }\end{array}$ & 55.69 & 30.09 & Anti-inflammatory & Anupama et al , 2014 \\
\hline 6 & $\begin{array}{l}\text { 2,4,4-trimethyl-3 hydroxymethyl-5A-(3Methyl-but- } \\
\text { 2enyl) cyclohexen }\end{array}$ & 6.068 & 31.17 & Anti-bacterial & $\begin{array}{l}\text { Sivakumar } \\
\text { Gayathri, 2015. }\end{array}$ \\
\hline
\end{tabular}

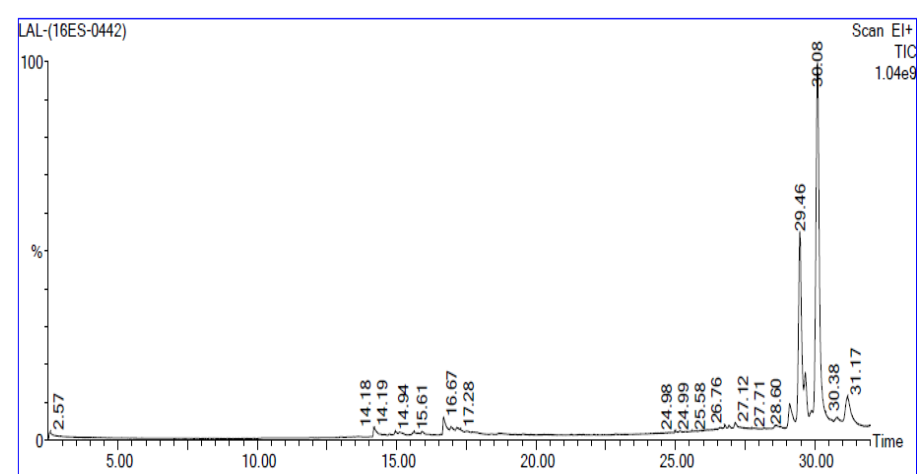

Figure 8 GC-MS analysis of extract of $C$. kissi wall. GC-MS spectrum of $C$. kissi wall. extract.

\section{Molecular Docking studies}

Docking studies revealed that, phytol exhibited a docking score of - 6.891 $\mathrm{kcal} / \mathrm{mol}$ for LasR which was relatively close to the binding energy of LasR with its natural ligand $(-7.293 \mathrm{kcal} / \mathrm{mol})$. Besides, 2R-Acetoxymethyl-1,3,3-trimethyl4t-(3-methyl-2-buten-1-yl)-1 T-cycloh and 2,4,4-Trimethyl-3-hydroxymethyl-5A(3-methyl-but-2-enyl) cyclohexen also exhibited a docking score of -5.675 and $5.81 \mathrm{kcal} / \mathrm{mol}$ respectively (Table 2, Figure 9). 
Table 2 Interaction of bioactive phytochemicals of $C$. kissi wall. with QS transcriptional regulatory protein, LasR of $P$. aeruginosa PAO1 represented in table with their docking score $(\mathrm{kcal} / \mathrm{mol})$, hydrogen bonds and hydrophobic residues.

\begin{tabular}{|c|c|c|c|c|}
\hline \multirow[b]{2}{*}{ SI No. } & \multirow[b]{2}{*}{ Compounds/Ligands } & \multicolumn{3}{|c|}{ LasR } \\
\hline & & $\begin{array}{l}\text { Docking score } \\
\text { (kcal/mol) }\end{array}$ & Hydrogen bond & Hydrophobic residues \\
\hline 1. & $\mathrm{C}_{12}$-HSL (Natural ligand) & -7.293 & Arg 61, Thr 75 & $\begin{array}{c}\text { Leu } 36, \operatorname{Tyr} 47, \operatorname{Trp} 60, \operatorname{Tyr} 64, \operatorname{Val} 76, \text { Tyr } \\
93, \operatorname{Thr} 115, \text { Ser } 129\end{array}$ \\
\hline 2. & Phytol & -6.891 & Leu 110 & $\begin{array}{c}\text { Tyr 47, Ala 50, Ile 52, Tyr 56, Arg 61, Tyr } \\
\text { 64, Ala 70, Tyr 93, Phe } 102\end{array}$ \\
\hline 3. & $\begin{array}{l}\text { 2R-Acetoxymethyl-1,3,3-trimethyl-4t-(3- } \\
\text { methyl-2-buten-1-yl)-1T-cycloh }\end{array}$ & -5.675 & Tyr 47, Arg 61 & $\begin{array}{l}\text { Leu 36, Ile 52, Ala 70, Asp 73, Val 76, Phe } \\
101\end{array}$ \\
\hline 4. & $\begin{array}{l}\text { 2,4,4-Trimethyl-3-hydroxymethyl-5A-(3- } \\
\text { methyl-but-2-enyl) cyclohexen }\end{array}$ & -5.81 & Tyr 93 & $\begin{array}{c}\text { Leu 36, Tyr 56, Trp 60, Thr 75, Phe 102, } \\
\text { Ser } 129\end{array}$ \\
\hline
\end{tabular}

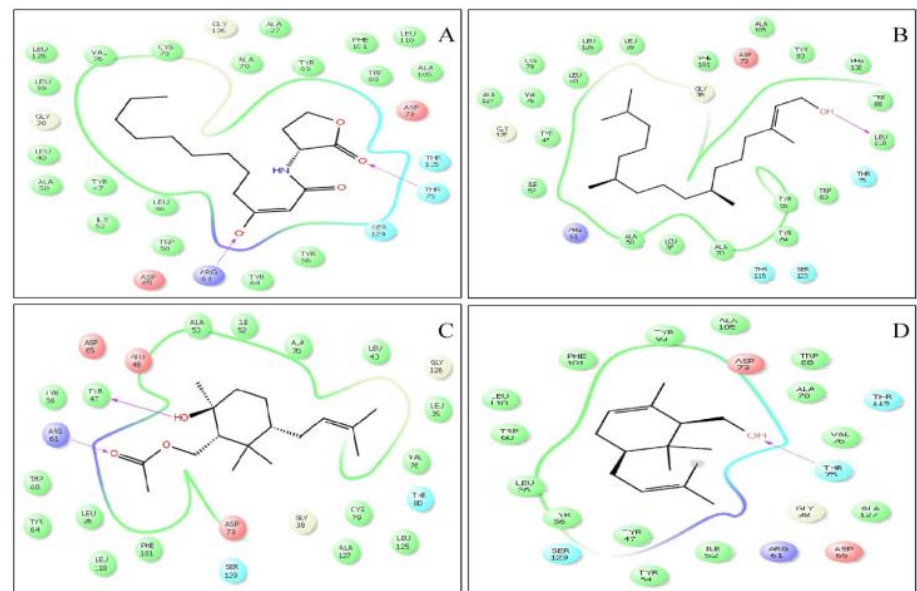

Figure 9 Molecular docking analysis of the phytochemicals identified from the ethanolic leaf extract of C. kissi wall. and their interactions with the QS transcriptional regulator protein, LasR as related to the interaction of natural ligand $\left(\mathrm{C}_{12}\right.$-homoserine lactone). (A). $2 \mathrm{D}$ picture revealing docking details of natural ligand, $\mathrm{C}_{12}-\mathrm{HSL}$ into the active pocket of LasR, (B) 2D picture showing docking details of phytol into the active site of LasR, (C) 2D docked conformation of 2R-Acetoxymethyl-1,3,3-trimethyl-4t-(3-methyl-2-buten-1-yl)1T-cycloh into the active site of LasR, (D) 2D docked shape of 2,4,4-Trimethyl3-hydroxymethyl-5A-(3-methyl-but-2-enyl) cyclohexen into the active site of LasR.

\section{DISCUSSION}

From ancient times, India constitutes a global hotspot of diversified medicinal plants with tremendous ethnomedicinal values, being used as folkloric medicines for the treatment of diseases, disorders and microbial infections. In this work, the ethanolic extract of $C$. kissi wall. was evaluated for its antioxidant potential and ability to attenuate QS mediated virulence and biofilm development. DPPH free radical scavenging assay is a gold standard to assess the free radicals scavenge potential of plant extract. C. kissi wall. plant extract was observed with a $\mathrm{IC}_{50}$ value of $238.95 \mu \mathrm{g} / \mathrm{mL}$. The antioxidant potential of C. kissi wall. was significantly higher than that of the Croton caudatus with an $\mathrm{IC}_{50}$ of 305.39 $\mu \mathrm{g} / \mathrm{mL}$ (Subhaswaraj et al. 2017b). The reducing power assay provide the ability of plant extract in reducing $\mathrm{Fe}^{3+}$ to $\mathrm{Fe}^{2+}$, which corresponds to the radical scavenging potential. In the present study, $C$. kissi wall showed an increase in reducing power along with increasing concentrations of extract, which was in accordance to the previous data (Baba et al., 2015). Hydroxyl radicals are one of the important members of ROS causing severe damage to biological macromolecules. Plant extracts based on their phytochemicals composition showed differential rate of scavenging to highly reactive hydroxyl radicals. In the present study, $C$. kissi wall. showed an increase in the hydroxyl radical scavenging with subsequent increase in concentrations of crude extract with an $\mathrm{IC}_{50}$ of $256.97 \mu \mathrm{g} / \mathrm{mL}$. This result was relatively very high as compared to methanol and chloroform extract of Kedrostis foetidissima with an $\mathrm{IC}_{50}$ of 2.0 and $2.8 \mathrm{mg} / \mathrm{mL}$ (Pavithra and Vadivukkarasi, 2015). The total antioxidant activity of plant extract was calculated according to the formation of phosphomolybdate complex and measured in terms of ascorbic acid equivalents. This plant extract exhibited an ascorbic acid equivalent of $137.12 \mu \mathrm{g} / \mathrm{mL}$. Total antioxidant activity of $C$. kissi wall. was nearly equal to that of Acacia nilotica leaf extract (ascorbic acid equivalent of $152.79 \mu \mathrm{g} / \mathrm{mL}$ ) (Subhaswaraj et al., 2017a).

The QS regulatory network provides an promising target for the formulation of novel anti-infectives from natural resources as it regulates the production of pathogenic determinants, biofilm formation, ROS generation and resistance to antibiotics. In this regard, QS inhibition has rose as an attractive target to mitigate infections and associated health risks caused by antibiotic resistance Ethanolic extract of $C$. kissi showed potent quorum sensing inhibition A sub-MIC level. The ethanolic extract of $C$. kissi wall. significantly regulated the production of violacein pigment as compared to untreated control in the biomarker strain, $C$. violaceum suggesting the efficacy of $C$. kissi wall. extract as potent QS inhibitor $P$. aeruginosa utilizes a highly complex cascade of QS network for the production of various of virulence phenotypes, siderophores, and most importantly several cytotoxic phenazine compounds, which play a significant role during host infection process. Pyocyanin is a highly toxic, ROS inducing phenazine compound and is an important biomarker during $P$. aeruginosa infection process and also involved in cytotoxicity (Chong et al., 2011). In the present study, C. kissi wall. potentially down-regulated the production of pycoyanin elucidating the ability of plant extract in minimizing the bacterial infection and cytotoxicity. The pyocyanin inhibition of $85.87 \pm 4.40 \%$ was significantly greater than the previous report where Terminalia bellerica showed $67.99 \%$ at $500 \mu \mathrm{g} / \mathrm{mL}$ (Ganesh and Rai, 2018). The swarming motility in $P$. aeruginosa is regulated by flagellar synthesis and alteration in flagellar synthesis could lead to reduction in swarming motility which corresponds to reduction in biofilm formation (Husain et al., 2017). C. kissi wall. potentialy inhibited the swarming motility of $P$. aeruginosa PAO1 as related to untreated control suggesting its ability to combat flagellar-driven biofilm formation. The biofilm disruption capacity of $C$. kissi wall. was further corroborated by CLSM analysis, which showed comparatively less thick and uncompact biofilm architecture (Packiavathy et al., 2014). The presence of phytol in the ethanolic leaf extract of C. kissi wall., as identified from GC-MS elucidated the efficacy of plant extract in scavenging free radicals and also combating QS regulated virulence and biofilm formation in P. aeruginosa PAO1 (Santos et al., 2013; Pejin et al., 2015). From the molecular docking studies, it was observed that phytol exhibited promising docking affinity with LasR which is relatively close to that of natural ligand suggesting the efficacy of phytol in competitive binding with LasR and altering the LasR mediated bacterial virulence.

\section{CONCLUSION}

The present study demonstrated the widespread potential of $C$. kissi wall. in scavenging highly reactive free radicals thereby suggesting its use as antioxidant for exogenous supplementation for maintaining the balance in the living system. In addition, the plant extract also act as potent inhibitor of QS regulated virulence and biofilm development in $P$. aeruginosa PAO1 by down-regulating the production of pyocyanin, inhibiting the bacterial motility and disrupting the recalcitrant biofilm architecture. The antioxidant and anti QS activity of $C$. kissi wall. could be assigned due to the presence of diverse group of phytochemicals including phytol, which has already been reported for antioxidant and anti QS properties. The present study will provide a lead in the antimicrobial drug discovery for the formulation of novel anti-infectives by recognizing the widespread potential of medicinal plants.

Acknowledgement: The authors are grateful to Bharathidasan University, Tiruchirappalli, Tamilnadu, India for providing the CLSM facility. The authors would also like to thank Sophisticated Instrumentation Facility (SIF), VIT University, Vellore, Tamilnadu, India for GC-MS analysis. The authors acknowledge the Centre for Bioinformatics, Pondicherry University for providing the molecular docking facility.

Conflict of interests: The authors declare no conflict of interests.

\section{REFERENCES}

Anupama, N., Madhumitha, G., Rajesh, K.S. (2014). Role of Dried Fruits of Carissa carandas as Anti-Inflammatory Agents and the Analysis of Phytochemical Constituents by GC-MS. Biomedical Research International, 2014, 512369. http://dx.doi.org/10.1155/2014/512369

Baba, S.A., Malik, A.H., Wani, Z.A., Mohiuddin, T., Shah, Z., Abbas, N., Ashraf, N. (2015). Phytochemical analysis and antioxidant activity of different tissue types of Crocus sativus and oxidative stress alleviating potential of saffron extract in plants, bacteria, and yeast. South African Journal of Botany, 99, 80-87. http://dx.doi.org/10.1016/j.sajb.2015.03.194 
Bashir, S., Khan, B.M., Babar, M., Andleeb, S., Hafeez, M., Ali, S., Khan, M.F (2014). Assessment of bioautography and spot screening of TLC of green tea (Camellia) plant extracts as antibacterial and antioxidant agents. Indian Journal of Pharmaceutical Sciences, 76(4), 364-370. http://dx.doi.org/10.4103/0250474X.139933

Bottomley, M.J., Muraglia, F., Bazzo, R., Carfi, A. (2007). Molecular insights into quorum sensing in the human pathogen Pseudomonas aeruginosa from the structure of the virulence regulator LasR bound to its autoinducer. Journal of Biological Chemistry, 282, 13592-13600 http://dx.doi.org/10.1074/jbc.M700556200

Cap, M., Vachova, L., Palkova, Z. (2012). Reactive oxygen species in the signaling and adaptation of multicellularmicrobial communities. Oxidative Medicine and Cellular Longevity, 2012, 976753 http://dx.doi.org/10.1155/2012/976753

Chong, Y.M., Yin, W.F., Ho, C.Y., Mustafa, M.R., Hadi, H.A., Awang, K., Narrima, P., Koh, C.L., Appleton, D.R., Chan, K.G. (2011). Malabaricone C from Myristica cinnamomea exhibits anti-quorum sensing activity. Journal of Natural Product, 74(10), 2261-2264. http://dx.doi.org/10.1021/np100872k

Do, Q.D., Angkawijaya, A.E., Tran-Nguyen, P.L., Huynh, L.H., Soetaredjo, F.E., Ismadji, S., Ju, Y.H. (2014). Effect of extraction solvent on total phenol content, total flavonoid content, and antioxidant activity of Limnophila aromatica. Journal of Food and Drug Analysis, 22(3), 296-302. http://dx.doi.org/10.1016/j.jfda.2013.11.001

El-Shaer, S., Shaaban, M., Barwa, R., Hassan, R. (2016). Control of quorum sensing and virulence factors of Pseudomonas aeruginosa using phenylalanine arginyl $\beta$-napthylamide. Journal of Medical Microbiology, 65, 1194-1204. http://dx.doi.org/10.1099/jmm.0.000327

Fernanades, C.P., Correa, A.L., Lobo, J.F.R., Caramel, O.P., De Almeida, F.B., Castro, E.S., Souza, K.F.C.S., et al. (2013). Triterpene esters and biological activities from edible fruits of Manilkara subsericea (Mart.) Dubard, Sapotaceae. Biomed Research International, 2013, 280810 http://dx.doi.org/10.1155/2013/280810

Ganesh, P.S., Rai, V.R. (2018). Attenuation of quorum sensing dependent virulence factors and biofilm formation by medicinal plants against antibiotic resistant Pseudomonas aeruginosa. Journal of Traditional and Complementary Medicine, 8(1), 170-177. http://dx.doi.org/10.1016/j.jtcme.2017.05.008

Gomathi, D., Kalaiselvi, M., Ravikumar, G., Devaki, K., Uma, C. (2015). GC MS analysis of bioactive compounds from the whole plant ethanolic extract of Evolvulus alsinoides (L.). Journal of Food Science and Technology, 52(2), 1212 1217. http://dx.doi.org/10.1007/s13197-013-1105-9

Husain, F.M., Ahmad, I., Al-Thubiani, A.S., Abulreesh, H.H., Alhazza, I.M., Aqil, F. (2017). Leaf extracts of Mangifera indica L. inhibit quorum sensing regulated production of virulence factors and biofilm in test bacteria. Frontiers in Microbiology, 8, 727. http://dx.doi.org/10.3389/fmicb.2017.00727

Hussein, H.M., Hameed, I.H., Ibraheem, O.A. (2016). Antimicrobial activity and spectral chemical analysis of methanolic leaves extract of Adiantum capillusveneris using GC-MS and FT-IR spectroscopy. International Journal of Pharmacognosy and Phytochemical Research, 8(3), 369-385.

Lewisoscar, F., Nithya, C., Alharbi, S.A., Alharbi, N.S., Thajuddin, N. (2018) Microfouling inhibition of human nosocomial pathogen Pseudomonas aeruginosa using marine cyanobacteria. Microbial Pathogenesis, 114, 107-115. http://dx.doi.org/10.1016/j.micpath.2017.11.048

Luis, A., Duarte, A., Gominho, J., Domingues, F., Duarte, A.P. (2016). Chemica composition, antioxidant, antibacterial and anti-quorum sensing activities of Eucalyptus globulus and Eucalyptus radiata essential oils. Industrial Crops and Products, 79, 274-282. http://dx.doi.org/10.1016/j.indcrop.2015.10.055

Meena, H., Pandey, H.K., Pandey, P., Arya, M.C., Ahmed, Z. (2012). Evaluation of antioxidant activity of two important memory enhancing medicinal plants Baccopa monnieri and Centella asiatica. Indian Journal of Pharmacology, 44(1), 114-117. http://dx.doi.org/10.4103/0253-7613.91880

Ogwuche, C.E., Amupitan, J.O., Ndukwel, G., Ayo, R.G. (2014). Isolation and biological activity of the triterpene B-Amyrin from the aerial plant parts of Maesobotrya barteri (Baill). Medicinal Chemistry, 4, 11. http://dx.doi.org/10.4172/2161-0444.1000221

Packiavathy, I.A., Priya, S., Pandian, S.K., Ravi, A.V. (2014). Inhibition of biofilm development of uropathogens by curcumin - an anti-quorum sensing agent from Curcuma longa. Food Chemistry, 148, 453-460. http://dx.doi.org/10.1016/j.foodchem.2012.08.002

Pavithra, K., Vadivukkarasi, S. (2015). Evaluation of free radical scavenging activity of various extracts of leaves from Kedrostis foetidissima (Jacq.) Cogn Food Science and Human Wellness, 4(1), 42-46. http://dx.doi.org/10.1016/j.fshw.2015.02.001

Pejin, B., Ciric, A., Glamoclija, J., Nikolic, M., Sokovic, M. (2015). In vitro antiquorum sensing activity of phytol. Natural Product Research, 29(4), 374-377. http://dx.doi.org/10.1080/14786419.2014.945088

Rajkumari, J., Dyavaiah, M., Sudharshan, S.J., Busi, S. (2018). Evaluation of in vivo antioxidant potential of Syzygium jambos (L.) Alston and Terminalia citrina Roxb. towards oxidative stress response in Saccharomyces cerevisiae. Journal of Food Science and Technology, 55(11), 4432-4439. http://dx.doi.org/10.1007/s13197-018-3355-z
Rath, S., Patra, J.K., Mohapatra, N., Mohanty, G., Dutta, S., Thatoi, H. (2011). In vitro antibacterial and antioxidant studies of Croton roxburghii $\mathrm{L}$., from similipa biosphere reserve. Indian Journal of Microbiology, 51(3), 363-368. http://dx.doi.org/10.1007/s12088-011-0133-2

Santos, C.C.M.P., Salvadori, M.S., Mota, V.G., Costa, L.M., De Almeida, A.A.C., De Oliveira, G.A.L., et al. (2013). Antinociceptive and antioxidan activities of phytol in vivo and in vitro models. Neuroscience Journal, 2013 949452. http://dx.doi.org/10.1155/2013/949452

Singh, B.N., Singh, B.R., Singh, R.L., Prakash, D., Dhakarey, R., Upadhyay, G., Singh, H.B. (2009). Oxidative DNA damage protective activity, antioxidant and anti-quorum sensing potentials of Moringa oleifera. Food and Chemical Toxicology, 47, 1109-1116. http://dx.doi.org/10.1016/j.fct.2009.01.034

Sivakumar, V., Gayathri, G. (2015). GC-MS analysis of bioactive components from ethanol extract of Andrographis paniculata. World Journal of Pharmacy and Pharmaceutical Sciences, 4(11), 2031-2039.

Subhaswaraj, P., Sowmya, M., Bhavana, V., Dyavaiah, M., Siddhardha, B. (2017b). Determination of antioxidant activity of Hibiscus sabdariffa and Croton caudatus in Saccharomyces cerevisiae model system. Journal of Food Science and Technology, 54(9), 2728-2736. http://dx.doi.org/10.1007/s13197-017-2709-2 Subhaswaraj, P., Sowmya, M., Jobina, R., Sudharshan, S.J., Dyavaiah, M., Siddhardha, B. (2017a). Determination of antioxidant potential of Acacia nilotica leaf extract in oxidative stress response system of Saccharomyces cerevisiae, Journal of the Science of Food and Agriculture. 97, 5247-5253. http://dx.doi.org/10.1002/jsfa.8409

Tounkara, F., Bashari, M., Le, G.W., Shi, Y.H. (2014). Antioxidant activities of roselle (Hibiscus sabdariffa L.) seed protein hydrolysate and its derived peptide fractions. International Journal of Food Properties, 17(9), 1998-2011. http://dx.doi.org/10.1080/10942912.2013.779700

Udayaprakash, N.K., Ranjithkumar, M., Deepa, S., Sripriya, N., Al-Arfaj, A.A., Bhuvaneswari, S. (2015). Antioxidant, free radical scavenging and GC-MS composition of Cinnamomum iners Reinw. ex Blume. Industrial Crops and Products, 69, 175-179. http://dx.doi.org/10.1016/j.indcrop.2015.02.018

Vasavi, H.S., Arun, A.B., Rekha, P.D. (2016). Anti-quorum sensing activity of flavonoid rich fraction from Centella asiatica L. against Pseudomonas aeruginosa PAO1. Journal of Microbiology, Immunology and Infection, 49, 8-15. http://dx.doi.org/10.1016/j.jmii.2014.03.012 